\title{
Complementary and alternative medicine use among HIV-infected patient's on anti-retroviral therapy in the Niger Delta Region, Nigeria
}

\author{
Alphonsus Udo Idung ${ }^{1}$, Festus Abasiubong ${ }^{2}$ \\ ${ }^{1}$ Department of Family Medicine, Faculty of Clinical Sciences, College Of Health Sciences, University of Uyo, Nigeria \\ ${ }^{2}$ Department of Psychiatry, Faculty of Clinical Sciences, College of Health Sciences, University Of Uyo, Nigeria
}

Email address:

dridung@yahoo.com (A. U. Idung), fesab200@yahoo.com (F. Abasiubong)

\section{To cite this article:}

Alphonsus Udo Idung, Festus Abasiubong. Complementary and Alternative Medicine Use among HIV-Infected Patient's on AntiRetroviral Therapy in the Niger Delta Region, Nigeria. Clinical Medicine Research. Vol. 3, No. 5, 2014, pp. 153-158. doi: 10.11648/j.cmr.20140305.19

\begin{abstract}
Background: Since the first case of HIV/AIDS was reported in Nigeria in 1986, HIV/AIDS has continued to penetrate the fabrics of all sectors of the Nigerian population. The plight of HIV/AIDS patients in Nigeria is made worse by inadequate supply of anti-retroviral (ARV) drugs. Methods: A prospective study was done between April and October 2013. Using a systematic sampling technique, 290 adult consenting male and female HIV/AIDS patients aged between 18 and 69 years who were on ARV drugs were recruited. They were assessed for use of complementary and alternative medicine (CAM) along with ARV drugs. Two research assistants assisted in data collection in a rural hospital using a semi-structured questionnaire. Results: Of the 290 subjects recruited, 259 (89.3\%) had their data analyzed, while data for 31 (10.7\%) subjects were discarded due to incomplete information. Subjects consisted of 101(39.0\%) males and 158(61.0\%) females. Of the 101 males 50(19.3\%) used CAM; compared to 100(38.6\%) females who also used CAM ( $\mathrm{p}=0.028)$. The mean age of CAM users was 34.39 ( $\mathrm{sd}=10-62$ ) years. Subjects between 29 and 49 years constituted the largest number of HIVinfected respondents who also used CAM. Subjects in the low income cadre patronized CAM more than those in the middle or higher income cadre $(\mathrm{p}=0.004)$. Herbal products were the most preferred CAM used by subjects in this study $(31.7 \%)$; and was followed by faith and prayer healing (14.7\%). Five (1.9\%) subjects drank urine as a form of therapy. Most subjects in this study preferred CAM because of the naturalness of their source and also because of concern that ARV drugs alone may not effectively manage their HIV/AIDS infection. Conclusions: CAM use is high among HIV/AIDS patients on ARV drugs in the Niger Delta region of Nigeria. Because of the possible risks of interactions following the concurrent use of CAM and ARV drugs, care givers involved in the care of HIV/AIDS patients should be vigilant in this regard.
\end{abstract}

Keywords: Anti-Retroviral Drugs, Complementary and Alternative Medicine (CAM), Niger Delta Region, Rural Hospital

\section{Introduction}

HIV/AIDS is a major threat to population health because of its effects on mortality trends, food security situation and health and education indicators of the society. Since the first case of AIDS was reported in Nigeria in 1986, HIV/AIDS has continued to penetrate the fabrics of all sectors of the Nigerian population. Globally, about 40 millions people are presently living with HIV/AIDS and millions have been killed by the same disease. Sub-Sahara Africa (SSA) is reported to be home to more than $70 \%$ of people living with HIV-worldwide. ${ }^{1}$.

Of the 15 million children under the age of 18 orphaned by HIV/AIDS in 2003, about 12 million were reported to live in sub-Sahara Africa. An additional 55 million deaths are projected in SSA between 2000 and 2020 as a result of AIDS, $39 \%$ more than would be expected without AIDS. ${ }^{2}$

With Nigeria population estimated to be above 160 million, Nigeria thus becomes the most populated country in SSA and is currently ranked as the country with the second highest burden of HIV in the world behind South Africa ${ }^{3}$

The Niger Delta region of Nigeria is home to certain percentage of people living with HIV infection (PLWA). 
There is a consistent upward trend in HIV seroprevalence among four of the six states in the region namely; Akwa Ibom. Bayelsa, Edo and Delta States. ${ }^{4}$.

HIV prevalence in Akwa Ibom State has remained relatively higher than those of other states in the region. The reported HIV seroprevalence for Akwa Ibom State rose from $8.0 \%$ in 2005 to $10.9 \%$ in $2010 .{ }^{3}$ Akwa Ibom State currently ranks second among the thirty six states of Nigeria in terms of HIV seroprevalence . ${ }^{4}$

HIV/AIDS scourge is made worse by the insufficient supply of anti-retroviral (ARV) drugs needed by those who are currently living with the disease. In Nigeria, a small number of government hospitals in several parts of the country are designated to supply basic anti-retroviral drugs to people with HIV/AIDS free of cost. However, only a fraction of those who need anti-retroviral drugs actually receive them, thus majority of Nigerians with HIV infection are without free medications. For instance, of the 6.5 million people in developing countries who need AIDS drugs, not up to a million receive it. ${ }^{5}$

As a result of this, and coupled with misinformation and myths surrounding HIV/AIDS infection, HIV infected persons resort to other avenues to get treatment. The readily available alternative to ARV drugs are traditional or complementary and alternative medicine. According to World Health Organization (WHO),Traditional medicine include diverse health practices, approaches, knowledge and benefits incorporating plants, animals and or mineral based medicines, spiritual therapies, manual techniques and exercises applied singularly or in combination to maintain wellbeing as well as to treat, diagnose or prevent illness. ${ }^{6}$

On the other hand, the United States National Centre for Complementary and Alternative Medicine (NACCAM) defines complementary and alternative medicine as a group of diverse medical and health care systems, practices and products that are not presently considered to be part of conventional medicine.

Complementary and alternative medicine (CAM) is used in place of traditional medicine in countries where the dominant health care system is based on the modern health care system and traditional medicine is seen as alien to the country's tradition and culture. In Nigeria, however, much of what is referred to as CAM is infact traditional medicine but the term CAM is used to described much of traditional medicine because of the seeming derogatory connotation of the term traditional medicine.

According to the World Health Organization (WHO), $80 \%$ of the populations of Africans use complementary and alternative medicine to help meet their health care needs. ${ }^{6}$

In Morocco, North Africa, $80 \%$ of patients with hypertension and diabetes mellitus are reported to have used medicinal plants to treat their ailments. ${ }^{8}$

In Enugu, South-East Nigeria, 65\% of cancer patient's reportedly used CAM and the various forms of CAM used were Herbs, faith/prayer healing, aloe vera, forever living products, medicinal tea and black stone. ${ }^{9} \quad$ Complementary and alternative medicine is also popular among patients infected with HIV. ${ }^{10}$

It is reported that about $75 \%$ of HIV-infected patients take some remedies from complementary or African Traditional medicine in South Africa. ${ }^{11}$

The reason for increased popularity of traditional/CAM among HIV-infected persons include the naturalness of its source, control of weight loss, nausea and diarrhea, need to fight opportunistic infections, boost immunity, relieve stress as well as the fear that ARV drugs alone may not be effective in the treatment of HIV/AIDS. ${ }^{12}$

It is however, reported that concurrent use of CAM with anti-retroviral therapy reduces adherence to HIV medications. ${ }^{13}$

Poor adherence to therapy would likely increase drug resistance with consequent rise in disease spread, a factor that might also contribute to increased HIV seroprevalence in some parts of Africa including the Niger Delta region of Nigeria. Published reports on the scope of traditional / complementary medicine use among HIV-infected patients on anti-retroviral therapy in the Niger Delta region are scarce in the scientific literature. The present study is aimed at describing the pattern of complementary and complementary medicine use among HIV-infected patients on anti-retroviral therapy in a rural Hospital in the Niger Delta region of Nigeria. It is hoped that findings from the study will add to the existing pool of knowledge in this regard.

\section{Materials and Methods Location of the Study}

This study was carried out at Qua Iboe Church Leprosy Hospital, Ekpene Obom in Etinan Local Government area of Akwa Ibom State of Nigeria. Nigeria is divided into six geo-political zones as follows: North-East, North-west, North-central, South-East, South-west and South-south. The south-south geopolitical zone is often referred to as the Niger Delta region of Nigeria. Akwa Ibom State is located in the Niger Delta region of Nigeria and has 31 local government areas. Etinan is one of the 31 local government areas of Akwa Ibom State. Qua Iboe Church leprosy hospital was established in 1932 in the rural Community of Ekpene Obom in present day Akwa Ibom State by Qua Iboe mission (QIM), as a leprosy settlement. The settlement has evolved over the years into a full-fledged district hospital. ${ }^{14}$

The hospital is presently run under a tripartite arrangement between Qua Iboe church Nigeria (QICN), Akwa Ibom State government (AKSG) and the leprosy mission. The hospital is currently affiliated to the department of family medicine of University of Uyo Teaching Hospital for training of medical students in leprology and tuberculosis control and treatment. The hospital currently has the following facilities namely: the general outpatient department (GOPD), the inpatient wards, an operating theatre, an eye clinic, a pharmacy unit, a physiotherapy unit as well as an HIV clinic for screening and dispensing of anti-retroviral (ARV) drugs. The HIV 
clinic holds on Tuesdays and Thursdays of every week.

\section{Subjects}

A total of two hundred and ninety (290) adult male and female subjects aged between 18 and 69 years attending the HIV clinic participated in the study. The sample size was determined using the formula $N=Z^{2} p(1-p) / d^{2}{ }^{15}$, where $\mathrm{N}$ is the minimum sample size, $\mathrm{Z}$ is the standard normal deviation set at $95 \%$ confidence level which corresponds to $1.96, \mathrm{P}$ is prevalence of $\mathrm{HIV}$-infected patients who also take some remedies from complementary or African traditional medicine (which is $75 \%$ ) ${ }^{11}$, while $\mathrm{d}$ is precision which at $95 \%$ interval is $5 \%$. Using the above formula, the calculated sample size was 288 .

Two hundred and ninety respondents were, however, recruited during the study period. They were recruited using a prospective random sampling method. Each recruited subject was given information regarding the research objectives after a written informed consent was obtained. Numbers ranging from one to three were assigned to the first three subjects who met the inclusion criteria. The first respondent was chosen by simply balloting one of the numbers from a basket containing the assigned numbers. Subsequently every third subject was recruited into the study. Where, however, a subject was adjudged to be too ill at the point of recruitment into the study, such a subject was dropped and the next subject who met the inclusion criteria was recruited. Subjects below 18 years of age were excluded. Ethical approval for the study was obtained from the University of Uyo Teaching Hospital Ethical committee. A pretest of the research proforma was performed to determine its applicability, experience and logistic problems.

\section{Methods}

This study took place between April 2013 and October 2013. Each of the subjects was assessed using an interviewer-administered pre-tested semi-structured questionnaire. Two research assistants consisting of one male and female were trained to assist in data collection. The content of training consisted of the need to create a more comfortable and trusting environment in which patients could freely and honestly report use of non-prescribed medicines in addition to ARV drugs. Data were collected on gender, age, marital status, highest level of education attained, religion, income (in Nigerian Naira denomination) using the approved wage structure in the Nigerian public service. ${ }^{16}$

Other information contained in the questionnaire included types of complementary and alternative remedies used, reasons given by the respondents for concurrent use of complementary and alternative medicine and ARV drugs.

\section{Data Analysis}

The statistical analysis was done using SPSS 17.0, distribution and cross tabulation was generated, chi square was used to compare proportions. The p-value of 0.05 was used to determine the level of statistical significance.

\section{Results}

Of the 290 respondents recruited into the study, 259 $(89.3 \%)$ respondents had their data analyzed, while 31 $(10.7 \%)$ respondents had volunteered incomplete information and as such their data were not analyzed. Fifty (19.3\%) male HIV-infected respondents who were on treatment with anti-retroviral drugs also used CAM remedies compared to one hundred (38.6\%) female respondents who also used anti-retroviral drugs, $(\mathrm{P}=0.028)$.

Table 1: shows the socio demographic characteristics of the respondents. The mean age of HIV-infected respondents on anti-retroviral drugs who also used CAM remedies was $34.39(\mathrm{sd}=10.62)$ years. Respondents between 29 and 49 years of age constituted the largest number of HIV-infected patients on ARV drugs who also used CAM remedies. HIVinfected respondents who belonged to the low income group patronized CAM remedies more than those in the middle or higher income level, $(\mathrm{P}=0.004)$.

Table 1. Socio Demographic Characteristics of HIV-Infected Respondents on Anti-Retroviral Drugs

\begin{tabular}{|c|c|c|c|}
\hline Variables & $\begin{array}{l}\text { Cam Users } \\
\mathrm{N}(\%)\end{array}$ & $\begin{array}{l}\text { Non-Cam } \\
\text { Users N(\%) }\end{array}$ & P-Value \\
\hline \multicolumn{4}{|l|}{ Sex } \\
\hline Male & $50(19.3)$ & $51(19.7)$ & $0.028 *$ \\
\hline Female & $100(38.6)$ & $58(22.4)$ & \\
\hline \multicolumn{4}{|l|}{ Age (In Years) } \\
\hline Up to 29 & $52(20.1)$ & $40(15.4)$ & \\
\hline $30-39$ & $46(17.8)$ & $38(14.7)$ & \\
\hline $40-49$ & $40(15.4)$ & $25(9.7)$ & 0.771 \\
\hline $50-59$ & $8(3.1)$ & $3(1.2)$ & \\
\hline $60-69$ & $4(1.5)$ & $3(1.2)$ & \\
\hline \multicolumn{4}{|l|}{ Marital Status } \\
\hline Single & $36(13.9)$ & $33(12.7)$ & \\
\hline Married & $84(32.4)$ & $64(24.7)$ & \\
\hline Divorce/sep. & $22(8.5)$ & $8(3.1)$ & 0.266 \\
\hline Widowed & $8(3.1)$ & $4(1.5)$ & \\
\hline \multicolumn{4}{|l|}{ Income (In Naira)** } \\
\hline Low level & $111(42.9)$ & $98(37.8)$ & \\
\hline Middle level & $32(12.4)$ & $9(3.5)$ & $0.004 *$ \\
\hline High level & $7(2.7)$ & $2(0.8)$ & \\
\hline \multicolumn{4}{|l|}{ Level of Education } \\
\hline No formal education & $5(1.9)$ & $3(1.2)$ & \\
\hline Primary School & $22(8.5)$ & $13(5.0)$ & 0.802 \\
\hline Secondary school & $100(38.6)$ & $72(27.8)$ & \\
\hline $\begin{array}{l}\text { Post secondary } \\
\text { school }\end{array}$ & $23(8.9)$ & $21(8.1)$ & \\
\hline \multicolumn{4}{|l|}{ Religion } \\
\hline Christianity & $124(47.9)$ & $101(39.0)$ & \\
\hline Islam & $8(3.1)$ & $5(1.9)$ & \\
\hline $\begin{array}{l}\text { Traditional } \\
\text { Worshipper }\end{array}$ & $11(4.2)$ & $2(0.8)$ & 0.058 \\
\hline None & $7(2.7)$ & $1(0.4)$ & \\
\hline
\end{tabular}

Statistically significant (Likelihood Ratio). 160 Naira $=\$ 1.00$ 
Table 2: shows the breakdown of CAM remedies used by HIV infected respondents on anti-retroviral drugs (ARDs). Herbal drugs were the most consumed CAM products among respondents in this study accounting for $31.7 \%$, and was closely followed by faith and prayer healing, 14.7\%). Five $(1.9 \%)$ respondents drank their urine as a form of therapy.

Table 2. Breakdown of Cam Products Used by HIV-Infected Respondents on Anti-Retroviral Drugs *

\begin{tabular}{ll}
\hline Types & Frequency of use $\mathbf{n}(\%)$ \\
\hline Biological Products & \\
Herbal drugs & $82(31.7)$ \\
Forever living Products & $23(8.9)$ \\
Aloe vera & $14(5.4)$ \\
GNLD & $30(11.6)$ \\
Tianshi products & $20(7.7)$ \\
African apple & $10(3.9)$ \\
Medical tea & $6(2.3)$ \\
Green tea & $6(2.3)$ \\
Scent leaf & $2(0.8)$ \\
Caster oil & $1(0.4)$ \\
Urine therapy & $5(1.9)$ \\
Honey & $8(3.1)$ \\
Bitter leaf & $10(3.9)$ \\
Edmark products & $29(11.2)$ \\
Kedi products & $19(7.3)$ \\
Spiritual Therapy & \\
Faith/prayer healing & $38(14.7)$ \\
Visualization & $1(0.4)$ \\
Transcendental meditation & $4(1.5)$ \\
Mental imagery & $1(0.4)$ \\
Psychic therapy & $1(0.4)$ \\
Alternative System & \\
Chinese medicine & $17(6.6)$ \\
Homeopathy & $8(3.1)$ \\
Acupuncture & $10(3.9)$ \\
Physical Therapy/Body Manipulation \\
Massage & $18(6.9)$ \\
Manual healing & $1(0.4)$ \\
Osteopathy & $1(0.4)$ \\
Others & \\
Ritual sacrifice & $11(1.5)$ \\
Shark cartilage & \\
Crude oil & \\
\hline
\end{tabular}

multiple responses given

Table 3: shows the reasons given by respondents for concurrent use of CAM remedies and anti-retroviral (ARV) drugs; $34.7 \%(\mathrm{n}=90)$ respondents preferred CAM remedies because of the naturalness of its source; $15.4 \% \quad(n=40)$ respondents used CAM remedies because it assists them to gain weight. Thirty, $11.6 \%(n=30)$ respondents used CAM remedies because it boosts their immunity. Two, $0.8 \%(n=2)$ respondents used CAM remedies because of their stress modulating effects; $8.9 \%(\mathrm{n}=23)$ respondents used CAM remedies because they help to fight opportunistic infections; while $28.6 \% \quad(n=74)$ respondents used CAM remedies because of the feeling that ARDS alone will not be effective in managing their HIV-infection.

Table 3. Reasons Given by Respondents for Concurrent Use of Cam Remedies and Anti-Retroviral (ARV) Drugs

\begin{tabular}{|c|c|c|}
\hline Reasons & Frequency & Percentage \\
\hline \multicolumn{3}{|l|}{ Cam Remedies Are } \\
\hline Natural & 90 & 34.7 \\
\hline \multicolumn{3}{|l|}{ Cam Remedies Help } \\
\hline In Weight Gain & 40 & 15.4 \\
\hline \multicolumn{3}{|l|}{ Cam Remedies Help to } \\
\hline \multicolumn{3}{|l|}{ Promote and Boost } \\
\hline Immunity & 30 & 11.6 \\
\hline \multicolumn{3}{|l|}{ Cam Remedies Help } \\
\hline \multicolumn{3}{|l|}{ To Relieve Stress } \\
\hline And Promote Health & 2 & 0.8 \\
\hline \multicolumn{3}{|l|}{ Cam Remedies Help } \\
\hline \multicolumn{3}{|l|}{ To Fight Opportunistic } \\
\hline Infections & 23 & 8.9 \\
\hline \multicolumn{3}{|l|}{ Arv Drug Alone } \\
\hline May Not be Effective & 74 & 28.6 \\
\hline
\end{tabular}

\section{Discussion}

Findings from this study show that women constituted the majority of HIV-infected respondents on anti-retroviral drugs who also used complementary and alternative medicine $(\mathrm{P}=.028)$. This finding is consistent with the sex distribution of HIV infection in Nigeria. HIV-infection prevalence in Nigeria is currently reported to be higher among females $(4.0 \%)$ than males $(3.2 \%)$ with girls and women showing higher early vulnerability and infections than boys and men. ${ }^{3}$

The prevalence of CAM use among respondents in this study was $27.9 \%$. This finding is lower than $75 \%$ reported in the literature for South Africa but less than $8.9 \%$ reported by another study in Pretoria South Africa. ${ }^{11,17}$

The reason for this wide disparity may be due to the methodology used or the population studied as well as cultural and social factors that bother on perceived causes of HIV-infection which might influence choice of remedy. HIV-infected respondents who belonged to low income level patronized CAM remedies more than others $(\mathrm{P}=0.004)$. This finding is consistent with the basic sociodemographic characteristic of people living with HIV/AIDS in the Niger Delta region. The region has the largest concentration of people living with HIV/AIDS in Nigeria and in spite of huge crude oil deposits in the region, it also has widespread decaying infrastructure and poor health care facilities, ${ }^{3,18}$ the recourse to CAM remedies is therefore a fall out of the inability of HIV-infected individuals to access anti-retroviral (ARV) drugs. 
Herbal drugs was the most preferred CAM remedy (31.7\%) used by respondents in this study. This is similar to a report from western Uganda which shows that majority of AIDS outpatients $(63.5 \%)$ were using traditional herbal medicine after HIV diagnosis. ${ }^{19}$

The popularity of herbs among HIV infected persons in the Niger Delta region of Nigeria may be related to its easy availability, the naturalness of its source as well as the belief in the supernatural cause of diseases among most Nigerians including Niger Delta residents. ${ }^{20}$

Faith and prayer was another most preferred CAM remedy $(14.7 \%)$ among respondents in this study. This is consistent with another report which shows that faith healing methods were popular among HIV-infected patients on anti-retroviral (ARV) drugs. ${ }^{21}$

The popularity of this mode of treatment is that religion is an acknowledged source of coping technique when dealing with difficult life situations ${ }^{22}$.

Respondents in this study gave diverse reasons for concurrent use of CAM and anti-retroviral drugs. Some respondents $(34.7 \%)$ preferred CAM because of the naturalness of its source; others $(28.6 \%)$ thought that antiretroviral drugs alone will not be sufficient for the management of HIV/AIDS. This is similar to report by other workers which shows that HIV-infected persons use CAM remedies for diverse reasons such as to fight weight loss, nausea and diarrhoea and to boost immunity and relief stress $^{23}$.

\section{Conclusion}

CAM use is high among HIV infected patients on antiretroviral drugs in the Niger Delta region of Nigeria. Because of the high prevalence of CAM use and multiple medications among HIV-infected individuals, possible CAM adverse events and interactions with HIV-treatments should be closely monitored by care givers.

\section{Recommendations}

Given the high prevalence of CAM use among HIV infected patients on anti-retroviral drugs in this study, and the risk associated with non-disclosure of concurrent use of CAM and ARV drugs, it is hereby recommended that all physicians involved in the care of HIV-infected patients should inquire from their patients about possible CAM patronage. Effective intervention programme that would help to increase physicians' knowledge about CAM use is hereby recommended. Physicians and other caregivers of HIV-infected persons need some more training on motivational interviewing techniques to be effective in inquiring about patients' medical histories, anti-retroviral therapy adherence as well as other aspects of care. From the patients perspective, targeted education programmes toward those who are vulnerable (young, women, low-level income earners) should be carried out to increase their health consciousness and awareness.
Limitations: The major limitation of this study is that we did not evaluate information on co-morbidities, which could be another reason for CAM use among the respondents.

\section{References}

[1] UNAIDS. The AIDS pandemic in the $21 \mathrm{st}$ century. International population reports 2004.

[2] Joint United Nations Programme on HIV/AIDS. 2000. Report on the Global HIV/AIDS Epidemic Geneva: UNAIDS.

[3] National Agency for the Control of AIDS (NACA), Federal Republic of Nigerian, Global AIDS Response Country Progress Report, GARPR 2012, Abuja, Nigeria.

[4] Federal Ministry of Health (Nigeria).National HIV/AIDS and reproductive Health Survey, 2007 (NARHS plus) Abuja Nigeria, Federal Ministry of Health 2008.

[5] United States Agency for development (USAID) and World Health Organization (WHO) 2004. Report on the Global AIDS Epidemic, Washington DC, USAID; Geneva: WHO.

[6] World Health Organization. 2002. WHO Traditional Medicine Strategy 2002-2005. Geneva: WHO.

[7] National Centre for Complementary and Alternative Medicine/ available at http://www.nccam,nih.gov/accessed 18.112013.

[8] Edduoks M, Maghrani M, Lemhadri A, Ouahidi ML, Jouad H. Ethno -pharmacological Surrey of Medicinal plants used for the treatment of diabetes mellitus, hypertension and cardiac diseases in the South-East Region of Morocco. J Ethno. Pharmacol. 2002; 82 (23): 97-105.

[9] Ezeoma ER, Anarado A N. Use of Complementary and Alternative Medicine by Cancer patients at the University of Nigeria Teaching Hospital, Enugu. BMC Complementary and Alternative Medicine 2008; 7:28.

[10] Duggan J, Peterson WS, Schutz M, Khuder S, Charkraborty J. Use of Complementary and Alternative therapies in HIVinfected patients. AIDS patient care STDs. 2001; 15: 159.167.

[11] Traditional Medicine;- Fact sheet No 134 (Revised May 2003 ) Geneva: WHO ,2003. Available at http://www.who.int/accessed 18.11-2013.

[12] Fairfield KM, Eisenberg DM, Davis RB, Libman H, Philips RS. Patterns of use, expenditures and perceived efficacy of Complementary and Alternative therapies in HIV-infected patients. Arch. Intern Medicine 1998; 158:2257-2264.

[13] Ekwunife OI, Oreh C, Ubaka CM. Concurrent Use of Complementary and Alternative Medicine with Antiretroviral therapy reduces adherence to HIV medications. Int. J. Pharm. Pract. 2012; 20(5) 340-3.

[14] Qua Iboe Leprosy Hospital, Ekpene Obom, Akwa Ibom State, Nigeria: A brief pictorial history of the hospital and the Rehabilitation programme 2007; 2-6. 
[15] Rao KV. Determination of Sample size IN: Rad KV, Seenayya G, (editors) .Biostatistics, A manual of Statistical Methods for use in Health, Nutrition and Anthropology, 2nd ed. Jaypee Brothers (medical publishers) (p) LTD, New Delhi 2007 pp 210-218.

[16] National Minimum wage Act Cap N61 Laws of the Federation of Nigeria 2004 as amended by Act 2011.

[17] Malangu N. Self-reported use of Traditional, Complementary and over-the counter medicines by HIVinfected patients on Anti-retroviral therapy in Pretoria, South Africa, Africa. J Trad. CAM. 2007; 4 (3): 273-278.

[18] Abasiubong F, Udoh SB, Idung AL, Umoiyoho AJ. Attitudes and sexual behaviours of unmarried people with HIV/AIDS living in the Niger Delta region of Nigeria. Mental Health in family medicine 2012; 9: 225-32.

[19] Langlois-Klassen D, Kipp W. Jhangri GS, Rubaac T. Use of Traditional Herbal Medicine by AIDS Patients in Kabarole District, Western Uganda .AmJ. Trop. Med. Hyg. 2007; 77(4): 757-63.
[20] Igoli JO. Ogaji OG, Tor-Anyim TA, Igoli NP. Traditional Medicine Practice amongst the Igede people of Nigeria, Part 11. Afr J. Traditional Complementary Alternative medicine $2005 ; 2: 134-52$.

[21] Peltzer K, Friend-du preez N, Ramlagan S, Fomumdam H, Anderson J. Traditional Complementary and Alternative Medicine and Anti-retroviral Treatment Adherence Among HIV Patients in KWAZULU-Natal, South Africa, Afr. J. Traditional, Complementary and Alternative Medicines 2010; 7(2): 125-137.

[22] Chinouya M, O' Keefe. God will look after Us: Africans, HIV and Religion in Million Keynes Diversity Health Soc. Care 2005; 2" 177-86.

[23] WiWanitkit V. The use of CAM by HIV-infected patients in Thailand Complementary Therapy Medicine 2003; 11: 3941 . 